교육과정평가연구

The Journal of Curriculum \& Evaluation

2003, Vol. 6, No. 2, pp. 371 391

\title{
컴퓨터 교육에서 정보윤리교육 내용 체계의 개선 방안
}

\author{
임진숙(한국교원대학교 박사과정) \\ 정영식(한국교원대학교 박사과정) \\ 김성식(한 국 교 원 대 학 교 )
}

\begin{abstract}
최근 정보화의 역기능 현상이 심각한 문제로 등장함에 떠라 학교에서의 체계적인 정보윤리교육 이 매우 중요시되고 있으며, 이러한 정보윤리교육은 ICT소양교육과 컴퓨터 교과 교육을 중심으로 이루어지고 있다. 현재 시행되고 있는 초등학교의 ICT소양교육ㄱ 중등학교의 컵퓨터교육과정에서 정보율리 관련 내용 체계에 연계성과 계열성이 부족하여 컴퓨터교과에서 교육해야 할 정보윤리 관 련 지식을 학생의 발달 수준에 맞게 계열화하고 체계적으로 조직할 필요가 있다.

이에 따라 본 연구에서는 ICT소양교육과 컴퓨터 교육교정에 포함된 정보윤리교육 내용 체계의 문제점을 표악하고, 미국의 컴퓨터 교육과정에 포함된 정보윤리 관련 내용 체계를 분석하며, 이를 토대로 우리의 컴퓨터 교육에서 정보윤리교육 내용 체계의 개선 방안을 제시하엿다.
\end{abstract}

주제어 : 정보윤리교육, 컴푸터교육, 정보윤리교육 내용 체계

\section{I . 서 론}

\section{1. 연구의 필요성 및 목적}

최근 인터넷 사용자 수가 급격히 증가하면서 컴퓨터 바이러스 유포, 개인 정보 유출 및 불건전 정보 유통과 같은 정보화의 역기능 현상이 심각한 사회문제로 대두되고 있다. 이러 한 역기능 현상을 해결하기 위한 장기적인 대응책으로 정보윤리교육이 매우 중요시되고 있 으며, 정부에서도 정보통신윤리교육 강화 방침을 제시하여 학교에서 체계적인 정보윤리교육 
을 시행할 것을 귄고하고 있다(기육부, 2000).

7차 교육과정에서 정보윤러교육과 관련된 내용을 살펴보면 도덕 교과와 컴퓨터 교과에 그 내용이 이느 정도 반영되어 있으며(교육부 - 한국학술정보원, 2001), 7차 교육과정 개정 훙 교욱부에서 발표한 정보통신기술교욱의 내용 체계에 '정보의 이해와 윤리' 영역이 포함되어 있다(기육부, 2000). 따라서 조·중등학피에서의 정보윤리기육은 ICT소양깅ㅇㄱ을 포함한 컴표 터 교육이 중심이 된다고 할 수 있다.

2001년부터 초능ㅎㅎㄱㄱㅛ 컴퓨터 교육이 푈수화됨에 따라 초등학교 컴퓨터 교육의 중심이 '실과'에서 ICT소양표욱으로서 컴푸터로 전환되었고, 표욱 내용의 준거는 정보통신기술교욷 운영지침에서 제시하는 ICT소양기육 내용 체계를 따르고 있다(기육부, 2000). 따라서 초·중등 학교 컴퓨터 기육은 초등학교의 ICT소양교육으로서 컴퓨터, 중학교 '컴퓨터', 고등학고 '정보 사회와 컥퓨터' 및 상업계 '컥퓨터 일반' 과독이 주축이 되고 있다.

현재 시행되고 있는 초등학교 컴퓨터 교욱은 ICT스양교욱의 내용 체계를 따르고 중등학 교는 제7차 컴푺터 교욱과정에 따라 컴퓪터 고욱이 이루어지고 있어서, 초·중등학교 컴푺터 교육이 이원화된 준거에 의해 실행되고 있다고 볼 수 있다. 이와 같은 현실에서 초·중등학 교 컴퓨터 표육의 계열성 면에서 문제점을 지적할 수 있으며(신은디 외, 2002), 여기에 한 부 분인 정보운리교육 또한 같은 문제를 가지고 있다고 할 수 있다.

ICT소양교욷의 내용 체계는 5개의 영역과 영역별로 5단계로 구성되어 있고, 그 중에서 정보윤러표육과 관련된 내용은 '정보의 이해와 윤리' 영역으로 설정되어 있으며, 이는 학생 의 발달 수준에 따라 융통성있게 저용할 수 있는 구체적인 한은 제시하고 있다. 이 너옹 체 계의 1 3단계의 내옹은 초등학교 컦퓨터 교육에 반영되괴 있으나 중등수준에서 표육되어질 4,5 단게 내용은 7차 교욱과정 컴퓨터 교과에 통합되지 못하여 컵퓨터 교욱을 수행하는 교 사의 의지에 따라 자유롟게 실행되고 있는 실정이다. 또한 중등학기 컴퓨터 기육과정에 포 함된 정보윤리교육에 관한 내용은 너투나 포괄적으로 기술되어 있고 중하교와 고등하교 교 육 내용의 계얼성이 버족하여, 이를 기준으로 개발된 중학고와 고등학교 표과서의 내용이 상당히 중복되어 있으며 깉은 학교근에서 사용되는 교과서 각에도 내옹 요슨와 게시 수준면 에서 많은 차이를 보이고 있다.

컴퓨터 고육은 통한 정보윤리교육의 이러한 문제를 해결하기 위해서는 초·중등학교의 전 과정에서 성취해야 할 정보윤리교육 목표를 설징하고, 이러한 목포플ㄹ 달성하기 위하여 정보율ㄹ 관련 지식과 교욱내옹을 학생의 발달 단계에 따라 계열화하여 보다 체계적으르 조 직할 푈오가 있다.

따라서 본 연구에서는 초·중등학교 컴퓨더 교육을 통한 정보윤리기육이 체게적으로 이 iㅜ어지도록 하기 위하여, ICT소양표육과 컴퓨터 교육과정에 포함된 정보윤리교육 나용 체계 의 계열성 면에서 문제점을 켜악하고, 이러한 문제를 개선하기 위하여 미국의 컦푸터 교육 
과정에 포함된 정보윤리 관련 내용 체계를 분석하여 시사점을 찾고, 이를 토대로 우리의 컴 퓨터 교육에서 정보윤리교육 내용 체계의 개선 방안을 탐색하고자 한다.

\section{2. 연구의 내용}

본 연구는 초·중등학교 컴퓨터 교과에서 정보윤리교육 니용 체계의 문제점을 파악하고 이에 대한 개선 방안을 제시하고자 다음과 같은 연구내용을 수행한다.

첫째, 컴퓨터 교육에서 정보윤리교육의 성격을 규명하고, 현재 시행되고 있는 ICT소양교 육과 컴퓨터 교육과정에 포함된 정보윤리교육 내용 체계를 조사한다.

둘째, 초·중등학교 컴퓨터 교과의 연계과목에서 정보윤리교육 내용 체계의 계열성을 분 석한다.

셋째, 미국의 컴퓨터 교육과정에 포함된 정보윤리교육 내용 체계를 분석하고 시사점을 찾아서 우리나라 정보윤리교육의 내용 체계에 대한 개선 방안을 제시한다.

\section{3. 연구의 방법}

컴퓨터 교육에서 정보윤리교육 내용 체계의 개선 방안을 제시하고자 다음과 같은 방법으 로 연구를 수행하였다.

첫째, 초·중등학교 컴퓨터 교과 교육의 실행 준거가 되고 있는 ICT소양교육의 내용 체 계와 중등하교 컴퓨터 교육과정에 포함된 정보윤리교육 내용 체계를 문헌 조사하였다.

둘째, 초등학교 ICT소양교육, 중학교 '컴퓨터', 고등학교 '정보사회와 컴퓨터' 과목 간에 정보윤리교육 내용 체계의 연계성을 분석하고 초등학교 컴퓨터 교육과 연결되는 ICT소양교 육의 4,5 단계 내용이 컴퓨터 교과에 어떻게 반영되었는지를 파악하며, 컴퓨터 교육과정의 편제 방식을 고려하여 정보윤리교육 내용 체계의 문제점을 제시하였다.

셋째, 우리의 정보윤리교육 내용 체계 개선에 대한 시사점을 찾고자, 독립교과로서 컴퓨 터 교육을 시행하고 있는 미국의 노스캐롤라이나 주의 컴퓨터 교육과정에 포함된 정보윤리 관련 내용 체계를 분석하여 정보윤리교육에서 중요하게 다루고 있는 내용요소가 무엇이고 이것을 어떻게 조직하고 있는지 살펴보았다. 


\section{II . 정보윤리교육}

\section{1. 정보윤리교육}

\section{가. 정보윤리교육의 개념}

정보윤리에 대한 학문적 관심은 컴퓨터 기술의 윤리적 문제를 다루기 위해 새로이 태동 한 컴퓨터 윤리학을 모체로 하고 있다. 1976년 월터는 컴퓨터 기술이 제기하는 문제들을 식 별하고 이를 해결하기 위해서는 컴퓨터 윤리학이라는 새로운 학문이 필요함을 주장하였다 (추병완, 2001). Moor(1995)는 컴퓨터 기술이 아주 새로운 형태의 특수한 윤리적 문제를 야기 하고 있다고 진단하면서 컴퓨터 윤리학은 컴퓨터 기술의 사회적 본질과 영항력을 분석하여 컴퓨터 기술의 윤리적 사용을 위한 정책의 입안과 정당화를 그 목표로 하는 학문이라고 정 의하였다. 이처럼 컴퓨터 윤리학은 컴퓨터 기술의 사용과 관련하여 기술이 야기하는 윤리적 문제를 인식하고, 사회적 영향력을 이해하며, 컴퓨터 기술의 윤리적 사용을 위한 정책(policy) 을 세우는 것을 주된 교육 목표로 삼고 있다.

우리나라에서도 정보사회에서 발생하는 역기능 현상과 윤리적 문제에 대한 대응책으로써 정보윤리교유의 중요성이 강조되고 있으며, 이는 정보사회에서 요구되는 윤리 의식의 함양 을 목적으로 하고 있다. 정보윤리교육은 정보통신기슬의 발전으로 인간이 새로운 가상 공동 체를 형성하고 그 속에서 다양한 활동들을 하게 됨으로써 수반되는 가상공간과 공동체 속에 서 인간이 지녀야 할 기본적인 도리 및 행동 양식을 가르치는 것으로 정의되고 있다(송태옥, 2001).

우리의 정보윤리교육은 앞서 살펴본 컴퓨터 윤리학과 비교해 볼 때 그 필요성과 목표 면 에서 큰 차이가 없다고 할 수 있다. 따라서 정보윤리교육은 정보사회에서 정보통신기술을 사용함으로써 발생하는 윤리적 문제를 인식하고 그 사회적 영향력을 이해하여 정보통신기술 을 올바르게 사용할 수 있는 윤리 의식과 행동 양식을 함양하도록 하는 교육이라고 말할 수 있다.

\section{나. 정보윤리교육의 내용}

컴퓨터 윤리학은 컴퓨터 기술의 사용으로 발생하는 윤리적 문제에 초점을 맞추고 있으 며, 컴퓨터 윤리학에서 다루어야 할 내용과 범위도 이러한 윤리적 문제를 중심으로 제시하 
고 있다. Johnson(1994)은 전무가의 직업 윤리, 소프트웨어의 소유퀸, 프라이너시, 범죄 ·남 용·해킹, 책임과 칙무, 컴퓨터의 사회적 영향으로서의 자윤성과 접근으로 나누어 보았고, $\operatorname{Edgar(1997)ㄴㅡㄴ~ㅅㅗㅍㅡㅌㅡㅇㅞㅇㅓ~ㅈㅓㅈㅏㄱㄱㅕㄴ,~ㅈㅣㅈㅓㄱ~ㅈㅐㅅㅏㄴㄱㅝㄴㅇㅢ~ㅊㅣㄴㅎㅐㅇㅘ~ㅂㅗㅎㅗ,~ㅋㅓㄱㅍㅠㅌㅓ~ㅂㅓㅁㅈㅚ,~ㅎㅐㅋㅣㅇㄱㅘ~ㅂㅏㅇㅣㄹㅓ~}$ 스, 사생활 침해, 소포트웨어의 에러와 신회성, 컴퓨터 세계에서의 자업, 전문가 운리, 정부 와 군대, 가상 세게의 9가지 영역에 대하여 윤리적 무제를 제시하였다. 그리고 Boywer(2001) 은 진문가의 윤리 강령, 해킹, 컴퓨터 시스템 보안, 암호화, 프라이버시, 컴퓨터 시스템의 안 전성, 내부 고발, 지적 재산견, 환경 및 긴강에 데한 염려, 공정성의 추국, 경력의 관리롤 강 조하였다.

한국학술정보원은 <표 1>과 같이 정보통신윤리 거육너용으로 통신예절, 불건전 정보 유 통, 통신 중됟게임, 사이버 성폭력/매매준, 언어 변형, 개인 정보의 오/남용, 통신 사기/도바, 해킹, 바이더스 유포, 저작권 칙해의 10 가지 영역에 데하여 교육목포와 너용을 상세하게 제 시하였다(유재택 외, 2000),

추병완(2001)은 한국학술정보원의 정보통신윤리 교우 내횽이 네티켓 외에는 전반적으로 정보화의 역기능만은 강조하고 있어서 균혐 감각은 상실하고 있다고 지젛하고, 정보통신윤 리 교육에서 중시해야 할 영역을 정보사회, 정보윤리, 네티켓, 대처요령의 크게 네 가지로 보았다. 
〈표 2) 정보통신윤리교육 목표 및 내용(유재택 외, 2000)

\begin{tabular}{|c|c|c|}
\hline . $\vec{r}$ 분- & 그육 팍 & 게눈 니욤 \\
\hline 1. 통신 예선 & $\begin{array}{l}\text { 사이버 동간에서 건진한 붕신푼화 } \\
\text { 조성을 위한 기논 예선법을 수득 } \\
\text { 시킨다. }\end{array}$ & 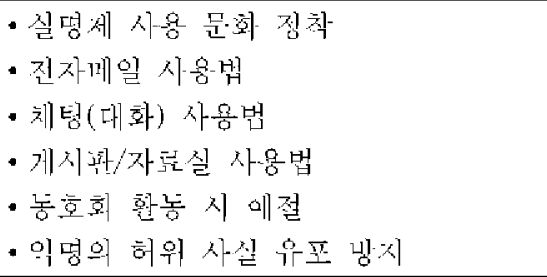 \\
\hline 2. 벌진전 싱노 유몽 & 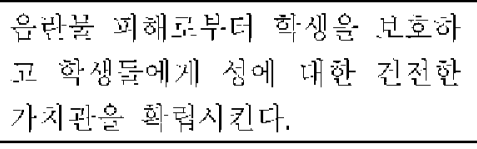 & 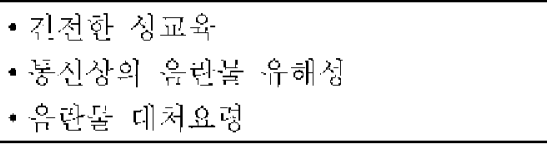 \\
\hline 3. 봉신 중녹/게읻 & $\begin{array}{l}\text { 학생둑에세 온바픈 놓신사용 즙퐌 } \\
\text { 을 습득하노녹 한다. }\end{array}$ & 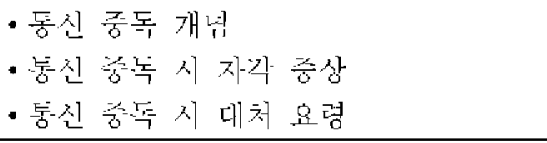 \\
\hline $\begin{array}{l}\text { 1. 사이버 청폭력/ } \\
\text { 매매현 }\end{array}$ & 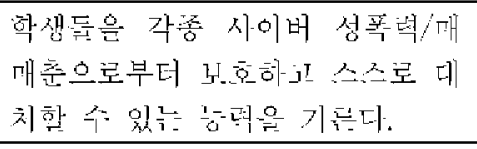 & 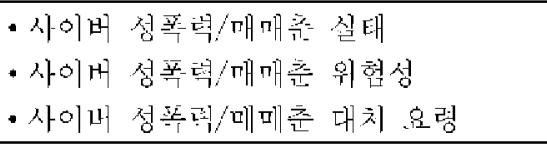 \\
\hline 5. 엄어 변형 & 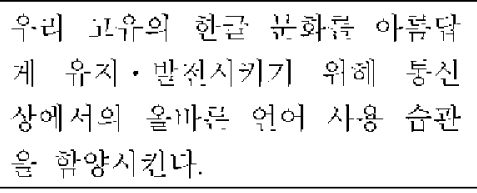 & 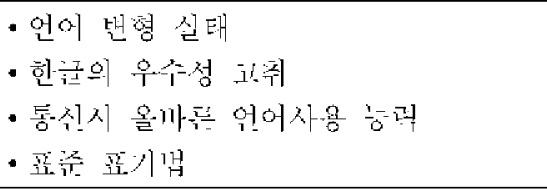 \\
\hline $\begin{array}{l}\text { 6. 개인 징보의 오/ } \\
\text { 남용 }\end{array}$ & $\begin{array}{l}\text { 개인의 프라이버시 보호를 위해 } \\
\text { 다임의 개입 정보를 존중하눈 문- } \\
\text { 화들 징착시킨나. }\end{array}$ & 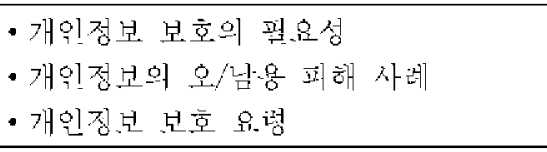 \\
\hline 7. 동신 사기/도바 & 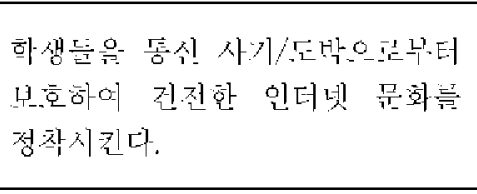 & 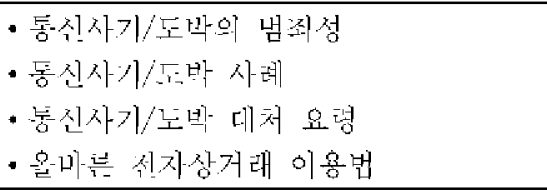 \\
\hline 8. 혜킹 & 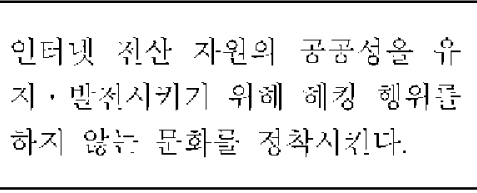 & 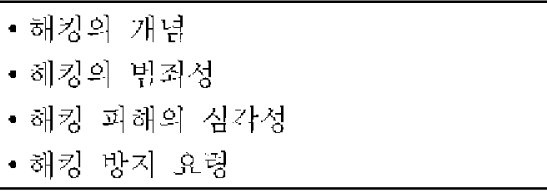 \\
\hline 9. 바이러스 유포 & 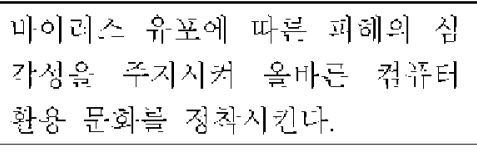 & 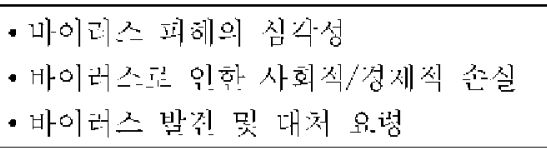 \\
\hline 10. 저작권 칩해 & 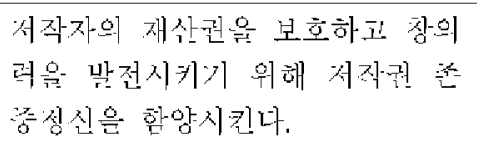 & 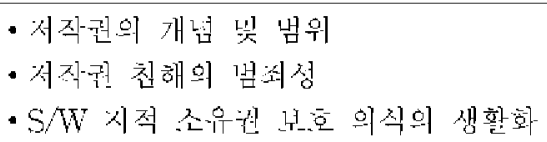 \\
\hline
\end{tabular}




\section{III . 컴퓨터교육을 통한 정보윤리교육}

\section{ICT소양교육에서 정보윤리교육}

ICT소양교육은 학교장 재량 홭동 시간이나 특별 활동 시간에 독립 고과 혹은 특겅 교과 의 내옹 영역오로 정보통신기술 자체에 관한 교육을 의미한다. 즉, 초등학교의 '실과'; 중학 교의 '컫퓨터', 고등학교의 '정보 사회와 컴퓨터' 교과릍 동해 학챙들이 컫퓨터, 가종 정보기 기, 멀티미디어, 응용프로그램을 다를 수 있는 기본적인 소양을 기르는 것을 말한다. 이러한 ICT소양고육의 나용은 5개영역으로 구분되며 각 영역은 수준별로 5단계의 내응으로 구성되 어 있다(이태욱 외, 2001).

ICT소양교육에서 정보윤리교육과 관련 있는 '정보의 이해와 윤리' 영역의 목표는 정보와 정보기기, 정보화 사회, 정보 윤리와 저작컨에 대하여 이해하고, 횔요한 정보를 올바로 선택 하고 횔용할 수 있도록 하는 것이다(교욲부, 2000) <표 2>는 이 영역의 단계별 세부 내용 및 활동은 보여주고 있두.

〈표 3〉 ICT 소양교육의 '접보의 이해와 윤리'영역 내용 체계

\begin{tabular}{|c|c|}
\hline 난게 잉역 & 정보의 이해와 유놔 \\
\hline 1 단 예 $(1 \sim 2$ 학년) & $\begin{array}{l}\text { - 징보기기의 이해 } \\
\text { - 정보와 생환 }\end{array}$ \\
\hline 2단계 (3-4학년) & $\begin{array}{l}\text { - 성보의 개념 } \\
\text { - 정보 율ㄹㅁㅇㅢ 이해 }\end{array}$ \\
\hline 3단ㄱㄱ $(5 \sim 6$ 학년 $)$ & $\begin{array}{l}\text { - 정보 횔용의 자세와 태드 } \\
\text { - 을바른 징번선텍과 환응 }\end{array}$ \\
\hline 4단계(7 9학년) & $\begin{array}{l}\text { - 정보 윤련와 제작권 } \\
\text { - 싱녀 사회의 개념 이해 }\end{array}$ \\
\hline 5난게 (10학넌) & $\begin{array}{l}\text { - 건전한 정보의 공유 } \\
\text { - 징버 사회와 일의 낸화 }\end{array}$ \\
\hline
\end{tabular}

초등학교의 컴퓨터 교욱이 필수화뒴에 따라 ICT소양교욱의 1-3단계 내용 체게에 따라 초 등학교 컴퓨터 피육이 이루어지고 있으며, 나머지 4단계의 5단게의 내용은 중등학표의 컴퓨 
터 관련 표고에 포함되거나 재량 활동, 특별 활동 그리고 므든 표과를 통하여 교육될 수 있 는 지침을 제공한다. 따라서 ICT소앙교육에서 설정하고 있는 '정보의 이해와 윤리' 영역의 독포를 달성하기 위해서는 중등학교 컴픁터 교육에 ICT소양교육의 4 , 5단게 내용이 반엉될 풜오가 있다.

\section{2. 컴퓨터 교육과정에 반영된 정보윤리교육}

7차 교욱과정의 컴퓨터 교과에서 성보윰러에 퐌한 내옹을 포함하고 있는 과목둘을 살펴 보면 대표적으로 중학교 '컴푸터', 고등학교 '정보사회와 컴푺터', 고등학교 '컴퓨터 일반' 과 목은 들 수 있다.

중화표 '컴퓨터'과목은 국민 공통 기본 교육과정의 7 -9하년에 포함된 재량 활동의 선택 과목으로, 정보 사회에서 기본적인 정보 소앙을 갂추기 위한 실천적 경험과 실성활에서의 활용성과 유용성을 중시하며, 정보화 사회에 적응할 수 있는 능력을 기르도록 하기 웨한 과 폭이다(기욖부, 1999).

고등학고 ‘정보사회와 컴퓨터' 과목은 5-6학년의 '실과', 7-9학년의 '기술·가정' 및 '컴 퓨터' 과목을 바탕으로 11 12 학년에서 선택하여 이수할 수 있는 과독으로, 정보화 사회어 필요한 정보 손양 능력을 길려 학습이나 일상생홀의 문제를 컴퓨터를 사용하여 즈스로 해결 할 수 있는 능력을 기르는 과똑이다. 그리고 '컴푸터 일반' 과목흔 상업 계열 공통 푈수 과 독으로서, 정보화 사회가 요구하는 직업인으로서 갖추어야 할 컴퓨터에 대한 기초전인 지식 과 기능을 습득할 수 있도록 구성된 기초 이론 과목이다(교육부, 1997).

중학표 '컴퓨터', 고등학표 '정보사회와 컴퓨터' 가목들은 공동적으로 정보화 사회에서 필 오로 하는 기본적인 정보 소양 능력을 기르고, 인상생활의 무제를 해결하기 위하여 이를 활 용할 수 있도록 하는 데 있으며, 고등학교 '컴퓨터 일반'과 같은 전문 고과에서는 미래의 직 업인으로서 갓추어야 할 능력을 기르는 데 중접을 뚜고 있다.

따라서 이러한 킴퓨터 과목에서 정보윰러표욱의 방향은 정보화 사회에서 발생하는 윤리 적 문제를 인식하고 이에 대한 대처 능럭과 정보톻신기술의 올바른 사용 능럭을 기르는데 있으며, 전묵 기과 과목에서는 미래의 직업 또는 전무 영역에서 정보통신기술의 사용과 관 련된 윤리적 문제를 인식하고 그와 같은 상황에서 올바른 사용 능력을 기를 수 있어야 한다.

이와 같은 컴퓨터 과목에서 교육과정에 반영된 정보윤리 고육내웅은 <표 3>과 같다. 
(퓨 4) 궉 ii 터 표과의 진코유리고듁 내륭

\begin{tabular}{|c|c|c|c|c|}
\hline ثاث & ut & 덩 & 세느 뎝억 & 니푸 \\
\hline$\stackrel{x}{i}$ & 隹-1 & 912 & 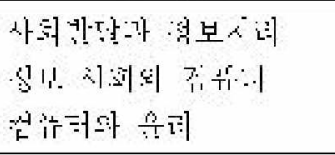 & 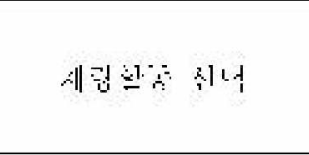 \\
\hline i'ו. & 성로사혜화 춥하더 & 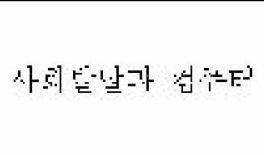 & 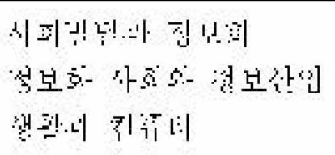 & 포놉 뇌겅 선피 \\
\hline & 넌뉴을 일만 & 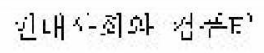 & 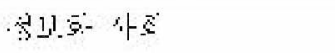 & 小山A \\
\hline
\end{tabular}

\section{3. 컴퓨터 교과이 정보윤리 교육내올 비교}

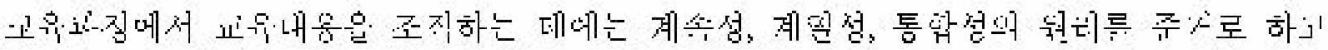

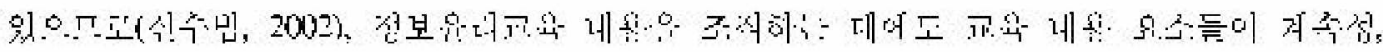

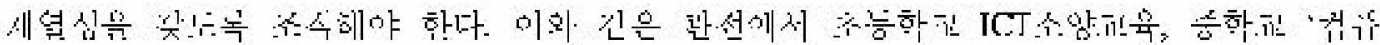

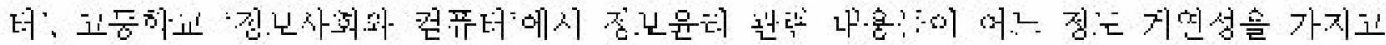

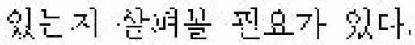

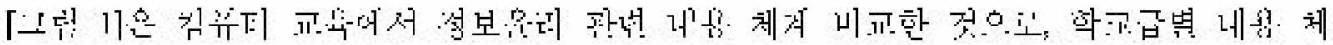

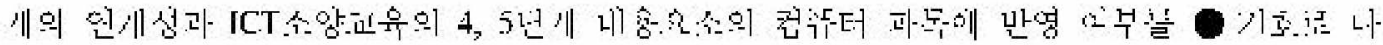
타나였다.

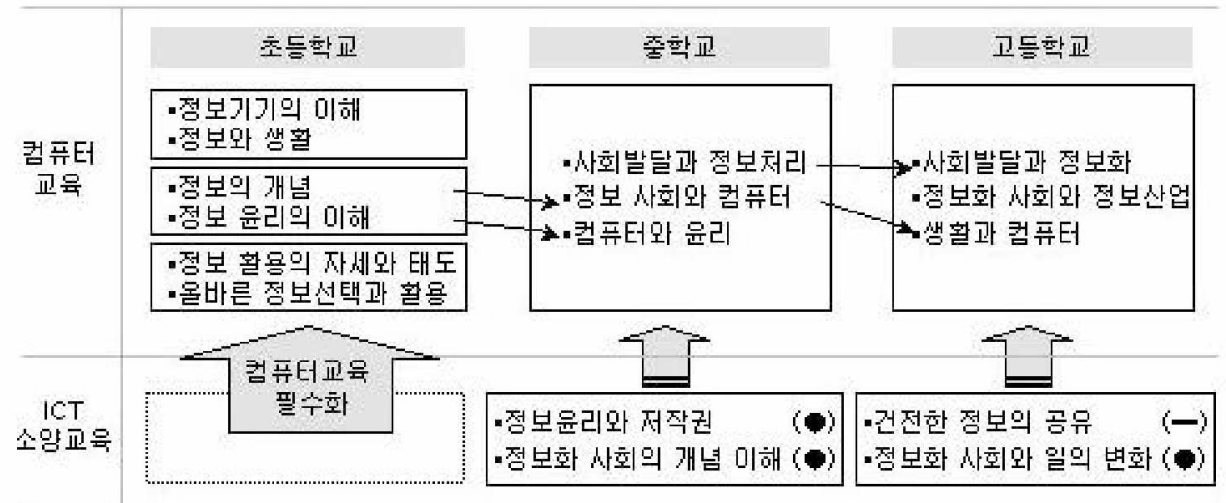

[소림 1] 겁끼터 교육메서 정보휴리 과려 너픙 체게 니교

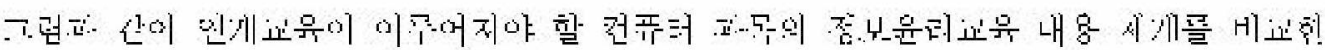




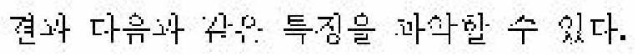

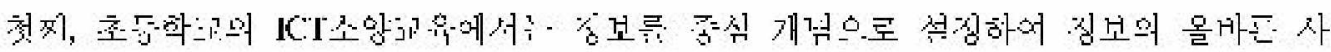

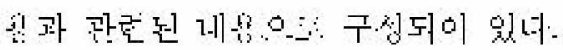

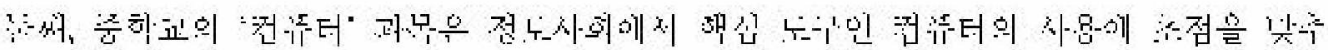

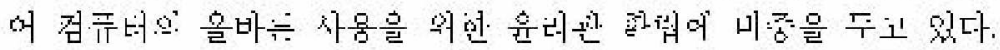

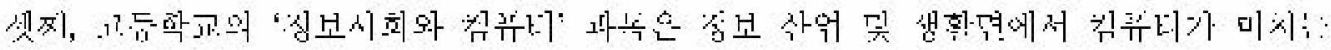

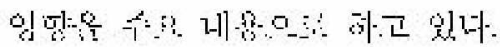

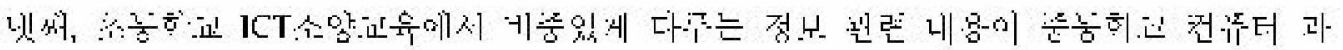
고어 벅계뇌지 곳하니 있다.

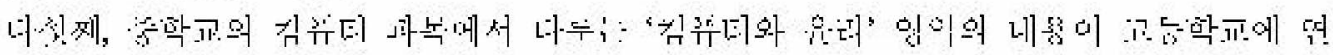

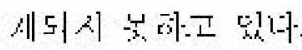

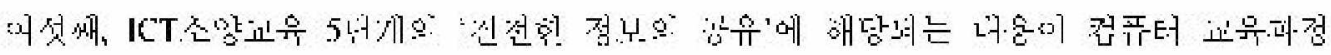
메 1,1-영되지 안기 있다.

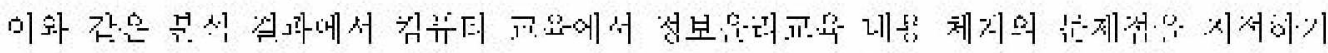

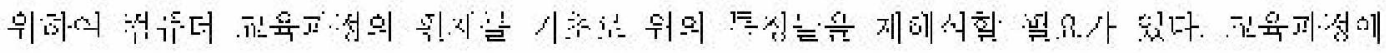

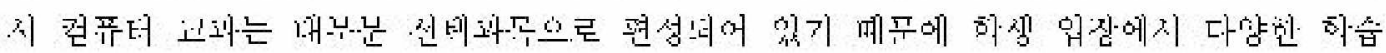

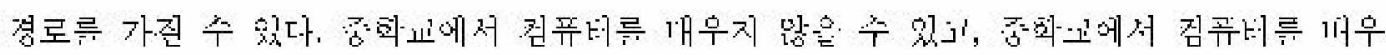

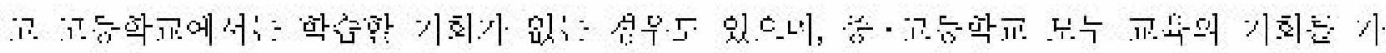

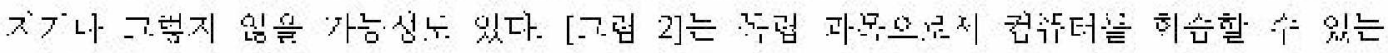
기봐 걸르를 니너준다.

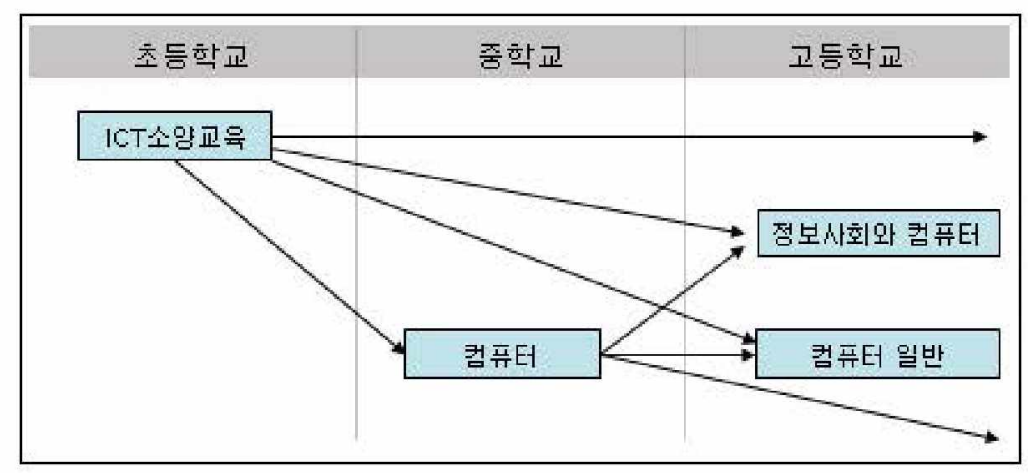

너리 2) 겁퓨커 학습 겁루

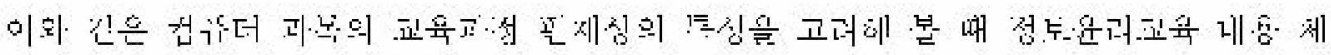

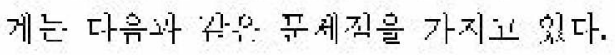


첫째, 초등학교 ICT소양교! 유과 중등학교 컴퓨터 과목의 나용 체게가 연계되어 있지 않다. 초등하표 ICT소양교육에서 중요하게 다루어지는 정보의 개념이 중학표와 고능학교 컴퓨터 과목에서 게속적이고 점차 심화, 확장되도록 조직되지 못하고 있다.

둘째, 중학고 “컴퓨터' 과목과 고등학고 “정보사회와 컴퓨터" 과목은 선택 과목이므로, 이 과몯의 니옹은 중복되도록 구성할 필오가 있으며 중등학피 단계에서 가육해야 할 내용 전반 을 다루어야 한다. 이러한 관점에서 불 때 중하표 컴퓨터에 포함된 '컴픂터와 윤리'에 영역 의 내용이 고등학교에 포함되어 있지 않아 중학교에서 '컦퓨터'과복을 선텍하지 않은 경우 컴푸ㄲㅓㅓㅇㅘ 관련된 윤리적인 문제를 학습할 기회를 가지지 못할 수 있다.

셋째, 고능확기에서는 중학기에서 다루는 내용을 계속정으로 다루어야 하지만, 같은 내용 이 단순히 중복되는 것이 아니라 중학교 보다 상위 단계의 심화된 관련 지식으로 구성될 푈 요가 있다.

이러한 분석을 종합적으로 놀 때, 현행 컴퓨터 교욱흘 통한 정보운리교욱의 내용 체계에 서 초등학교와 중등학교 교욱 내용의 연계성이 부족하고, 학생의 받달 수준을 고려하여 학 교급별로 교육되어야 할 내용 요소의 기즌은 제시하지 못하며, 고육되어야 할 세부 내옹의 영역을 중심으로 계열성이 부족하다는 문제점을 지적할 수 있다.

\section{IV. 미국의 K-12 컴퓨터 교육과정과 정보윤리교육}

우리나라의 초·중등학고 컴퓨터 교육에서 정보윤리교육 내용 체게의 계열성 부족의 문 게에 대한 개선 방안을 찾기 위하여 미국의 K-12 컫퓨터 교육과정의 사례를 통해 정보윤리 교욱에서 중요하게 다루고 있는 내용 요소가 무엇이고 이둘을 어떻게 체계적으로 조직하고 있는지 살펴보고자 한다.

뮈국은 학생들의 정보소양은 위하어 국가의 차원에서는 전국적인 학교망 구축과 같은 국 가 교육정보화 프로렉트를 수행하고 교육과정 개발은 각 주의 각 하교 구(School District)별 로 이룯어저서 구마다 독립직인 교욱을 실행한다(김영수 외, 2000).

각 주의 교훅ㄱ점 개발에 포준안을 제공하고사 ISTE(Intemational Society for Technology in Education)와 ACM 같은 단체에서는 Grade K-12의 기출 밎 컴퓨터 과학 긴유ㄱㅘㅘ정 기준인 을 개발하고 있으며, 이러한 기준안은 지방 정부에서 녹립적으로 기술 및 컴퓨터 표육과정 올 제정하는데 기초적인 모델이 되고 있다.

ISTE에서 개발한 NETS(National Educational Technology Standards)에는 기술 iㅛ유에서 K-12 학생들이 성춰해야 할 목폰 영역을 6가지로 설정하고 있으며, 그 중에 정보윤리와 관 
련된 'social, ethical, and human issues' 영역을 포함하고 있다.

최근 $\mathrm{ACM}$ 에서도 K-12 컴퓨터 과하 교육과정 모델을 개발하고 있는데, 이 교육과정 또한 NETS 모델올 기초로 'social, cthical, and human issucs' 영역올 통해 정보윤리교육올 하고 있 으며 이 영역에 대한 학생들의 성취 목표를 다음과 깉이 설정하고 있다.

학상들은 컴퓨터와 관련된 윤리적, 둔화적, 사회적 이슈를 이해한다; 컴퓨터, 정보, 소 프트웨어의 칙임있는 사용은 실행하고, 경생 학습, 홥력, 개인적인 일(pursuits), 상산성은 지원하는 컴퓨터 시용을 향한 긍징적인(positive) 태도를 개발한다.

학생들이 이러한 목포를 달성할 수 있도록 <포 4>와 같이 학년별 세부 목표를 제시하고 있으며, 그 중에서 초등학기에서 중학표에 해당하는 K-8 학년의 성취 믁포는 NETS 모델에 서 제안하고 있는 것은 -ㄷㄷ대로 수용하고 있다.

(표 6) K-12 컴표터 교육과정의 정보윤리 교육 내용 체계

\begin{tabular}{|c|c|}
\hline 학넌 & 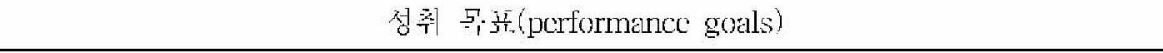 \\
\hline $\mathrm{K}-2$ & 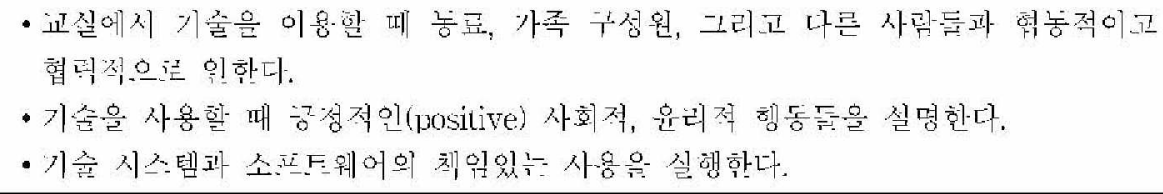 \\
\hline 35 & 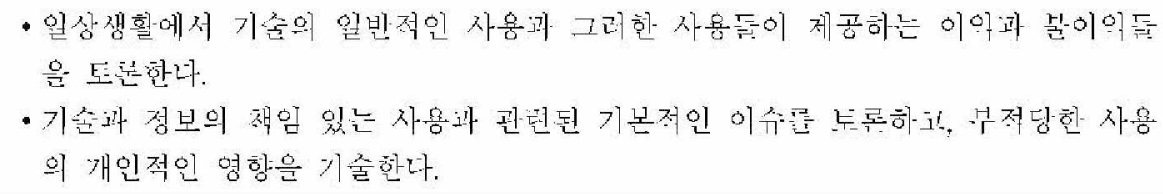 \\
\hline 68 & 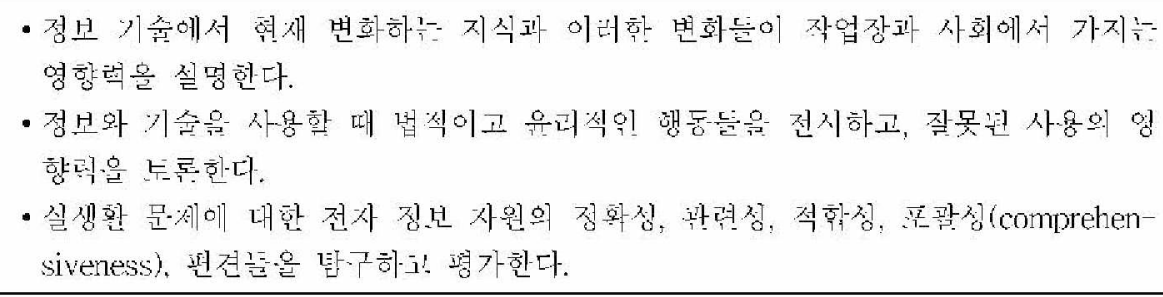 \\
\hline 9 or 10 & 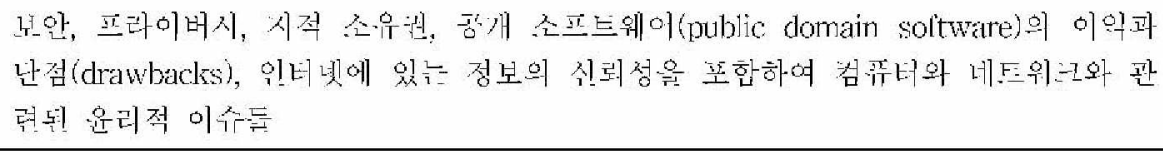 \\
\hline 10 or 11 & 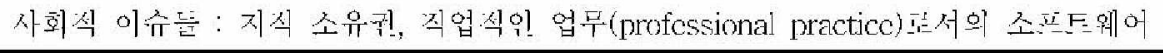 \\
\hline
\end{tabular}

그리고 미국의 노스캐롤라이나 주에서 개발한 컴퓨터/기술 기능(skills) 교육과정에서는 컴 
푶터 기육이 K-8학년가지 별도의 독립 기과로 이루어질 수 있도록 영역별 세부 내용 체게를 구성하고 있으며, 9-12화년은 다른 교과에 통합되어 교육되도록 하-고 있다.

노스캐롤라이나 주의 컥퓨ㅌㅓㅣ기술 기능 교육과정은 K-8학년까지 성춰해야 할 세 가지 능 력 목표를 설정하고 있으며, 그 중에서 정보윤리와 곽련 있는 능력 목표 1은 다음과 깉다.

학생둘이 기술 기반 사회의 중요한 쟁점을 이해하고 켬퓨터와 다른 기기의 사용에 있어서의 윤리적 행위를 보여줄 수 있도록 한다.

그리고 이 고육과정은 5가지 내웅 영역 중에서 사회적 이슈(Social Issucs) 영역을 설정하 여 정보울리교우을 위한 학년변 교욱 내용을 세부적으로 제시하고 있다. 다음 <표 5>는 사 회적 이슈(Social Issues)영역의 내용 체게를 나타내고 있다.

〈표 5-2〉노스캐롤라이나 컴퓨터/기술 기능 고육과정의 Social Issues 영역

\begin{tabular}{|c|c|}
\hline 7 & 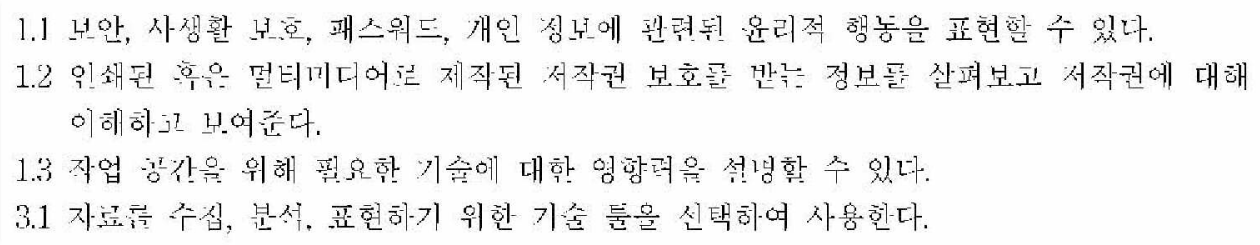 \\
\hline 8 & 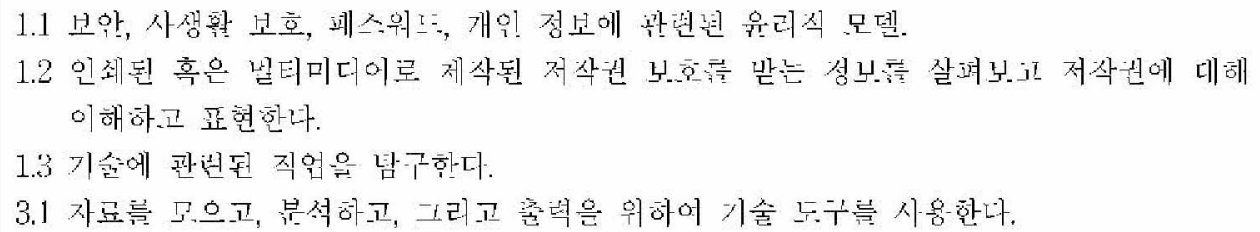 \\
\hline
\end{tabular}

본 연구에서는 킴퓨버/기술 기능 교우과정에서 설성하고 힜는 눙력 목표 1을 [그림 3]과 같이 세부 묵프로 분류하고 이를 준거로 정보윤리피육의 세 가지 내응 영역을 도출하였다. 


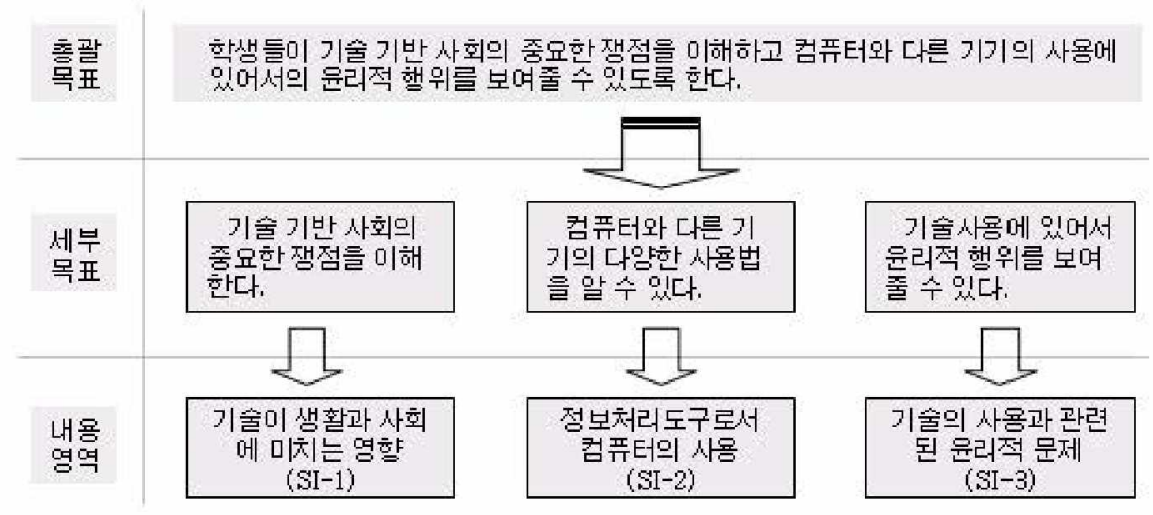

그림 3. 노스개를라이나 주의 점보뮨리교묵 목표뫄 네욤 형벅

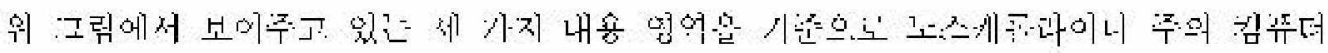

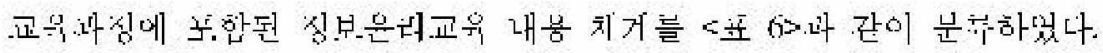


〈표 6) 노스캐롤라이나 컴퓨터/기술 기능 고육과정의 S| 엉역 분석

\begin{tabular}{|c|c|c|c|c|}
\hline 학년 & 내용 오소 & SI-1 & $\mathrm{SI}-2$ & $S I-3$ \\
\hline$k$ & $\begin{array}{ll}\text { SI } & 1.1 \\
\text { SI } & 1.2 \\
\text { SI } & 1.3 \\
\text { SI } & 1.4\end{array}$ & . & . & \\
\hline 1 & $\begin{array}{ll}\text { SI } & 1.1 \\
\text { SI } & 1.2 \\
\text { SI } & 1.3 \\
\text { SI } & 2.1\end{array}$ & - & - & " \\
\hline 2 & $\begin{array}{ll}\text { SI } & 1.1 \\
\text { SI } & 1.2 \\
\text { SI } & 2.1 \\
\text { SI } & 2.2\end{array}$ & - & - & " \\
\hline 3 & $\begin{array}{ll}\text { SI } & 1.1 \\
\text { SI } & 1.2 \\
\text { SI } & 2.1 \\
\text { SI } & 2.2\end{array}$ & - & - & - \\
\hline 4 & $\begin{array}{ll}\text { SI } & 1.1 \\
\text { SI } & 1.2 \\
\text { SI } & 1.3 \\
\text { SI } & 1.5 \\
\text { SI } & 2.1 \\
\text { SI } & 2.11\end{array}$ & - & $\begin{array}{l}. \\
. \\
\end{array}$ & - \\
\hline 5 & $\begin{array}{ll}\text { SI } & 1.1 \\
\text { SI } & 1.2 \\
\text { SI } & 1.4 \\
\text { SI } & 2.1 \\
\text { SI } & 2.2 \\
\end{array}$ & - & - & - \\
\hline 6 & $\begin{array}{ll}\text { SL } & 1.1 \\
\text { SI } & 1.2 \\
\text { SL } & 1.3 \\
\text { SI } & 1.4 \\
\text { SI } & 3.1 \\
\end{array}$ & - & - & $\begin{array}{l}. \\
.\end{array}$ \\
\hline 7 & $\begin{array}{lll}\text { SI } & 1.1 \\
\text { SI } & 1.2 \\
\text { SI } & 1.3 \\
\text { SI } & 3.1 \\
\end{array}$ & ॥ & - & - \\
\hline 8 & $\begin{array}{lll}\text { SI } & 1.1 \\
\text { SI } & 1.2 \\
\text { SI } & 1.3 \\
\text { SI } & 3.1\end{array}$ & - & - & - \\
\hline
\end{tabular}

